\title{
UMA EXPERIÊNCIA EM PSICOLOGIA, EDUCAÇÃO E COMUNIDADE
}

\author{
Salete Peters \\ Gustavo Gonçalves da Cunha \\ Raquel Tizzei \\ Centro Universitário Hermínio Ometto (Uniararas)
}

RESUMO: O trabalho integra a teoria e prática e reflete a atuação do psicólogo na área da educação inserido num contexto de comunidade. Propõe pensar sobre a questão da presença do adolescente e da criança no espaço escolar: o que representa este espaço? A literatura focaliza o ambiente e instituição escolar como sendo lugar da interação com o outro e nesta interação com o outro e com os outros ambientes dá-se o desenvolvimento. O compromisso da escola, dos educadores e do psicólogo educacional, será o de gerar possibilidades capazes de mediar um desenvolvimento saudável e libertador tornando os indivíduos criativos e autônomos. Os dados coletados nesta pesquisa deram-se por meio da pesquisa ação e registro em diário de campo. Conclui-se que o espaço escolar é buscado essencialmente como o lugar no qual se dá a interação com outro e da manifestação do potencial criativo o que implica um desenvolvimento saudável.

PALAVRAS-CHAVE: comunidade; escola; interação; desenvolvimento; libertação.

\section{AN EXPERIENCE IN PSYCHOLOGY, EDUCATION AND COMMUNITY}

ABSTRACT: This research integrates theory and praxis, considering the practice of educational psychologists inserted in the context of a community. It discusses the matter of teenagers and children being in school with the question: "what does this place represent"? The focus of literature on the environment and institution of a school highlights it as being the place of interaction with others. And, due to this interaction with others and with other environments, it's a place where development occurs. The school's job, from educators and educational psychologist, will be to engage in creating opportunities capable of interposing, on behalf of the students, a healthy and liberating development, rendering creative and self-governing individuals. Action research and a field diary were the methods used for collecting data. In conclusion, being at school is, essentially, a place where interactions with others and the manifestation of creative potentials occur, which implies a healthy developoment.

KEYWORDS: community; school; interaction; liberating development; healthy development.

Este trabalho tem como proposta olhar para a escola e a comunidade como espaço singular da constituição do sujeito social. As questões levantadas buscam nortear-se a partir da teoria de Bronfenbrenner (1996) e inclui: o desenvolvimento saudável que se realiza pelo estabelecimento de vínculos saudáveis e a interação entre os diversos níveis da sociedade. Decidiu-se articular a prática com a teoria identificando o espaço escolar como sendo gerador de possibilidades, por meio de vivências espontâneas ou dirigidas, na qual o sujeito projeta sua história explorando o espaço escola que inclui a comunidade como um todo nos seus diferentes e diversos grupos centros comunitários, sindicatos, prefeitura, centros culturais, permitindo a construção do cidadão em sua atividade criadora e singular. Frente a isso emergem duas atitudes do psicólogo e educador: acreditar no potencial do sujeito com o qual atua o que proporciona um desenvolvimento saudável; conhecer o contexto dentro do qual o sujeito se movimenta a partir do qual propõe sua atuação.

A atividade, o estar em movimento, a interação, são aspectos inerentes ao ser humano, faz parte de sua essên- cia, de seu ser. A paralisação, a inércia, levam a mesmice, é morte (Ciampa, 2001). Exige-se portanto, dos indivíduos uma atividade, que "façam algo", criem, recriem, se manifestem. Diante desse fato ontológico, a paralisação de um indivíduo ou de grupos é questionada: O que acontece com tal pessoa? Está doente?

A paralisação nos sugere sofrimento, doença. A atividade ao contrário suscita um estado de saúde bio-psisocial pois coloca o indivíduo num estado e capacidade para realizar efetivamente suas funções e tarefas para as quais foi socializado (Silva, 2002).

A atividade a partir da qual se dá a manifestação do indivíduo na sua totalidade, realiza o indivíduo e ao mesmo tempo manifesta o modo de vida, a sociedade, a personalidade e saúde (Rey, 2001). Isto indica que a atividade do sujeito não se dá de modo acidental ou por acaso, mas sempre em relação com um outro com o qual processa seu desenvolvimento, interagindo. O Homem só pode vir a se completar com outros. As pessoas se constituem e se completam na interação com os outros (Guzzo, 2005). 
Durante as atividades realizadas em "psicologia e comunidade", postos diante da movimentação de adolescentes e crianças, inquietou-nos o fato do constante sair e retornar na área escolar, e fez-se insistente a questão: por que este constante movimento de ir e vir? O que representa o espaço escolar para estas crianças e adolescentes e jovens?

O campo dentro do qual se deu nossa prática foi uma escola estadual, de ensino fundamental ( $5^{\mathrm{a}}$ a $8^{\mathrm{a}}$ série $)$ e ensino médio. Situa-se na cidade de Araras, São Paulo, Brasil. Nesta escola acontece o programa Escola da Família aos sábados e domingos. O objetivo deste programa é realizar uma prática que integre a comunidade e escola por meio de atividades culturais e de lazer. Estas atividades são organizadas pelos universitários que ali estão para obter a bolsa de estudos. Esporadicamente aparecem voluntários da comunidade integrando-se na tentativa de realizar projetos culturais, desportivos.

Segundo o relato e observação dos universitários este programa vem de encontro a uma necessidade da comunidade oferecendo um espaço às crianças e adolescentes que "estão na rua sem saber o que fazer", e ali, neste espaço, eles poderiam se proteger dos perigos da rua, sair de casa, fazer coisas diferentes, jogar, e acima de tudo não fazer malandragens. A partir disso começamos a nos perguntar: que rua é essa? Como são as ruas deles? Que tipo de peraltices eles costumam praticar? Como são as casas deles? E as famílias o que fazem? trabalham? Onde trabalham? O que existe do outro lado do muro da escola? e sobretudo: o que o programa oferece para que de fato se torne um lugar agradável e seguro?

Para saber teríamos que ir a campo. Decidimos então por os pés no chão e visitar as ruas do bairro. No início marcamos um horário querendo seguir um cronograma para não nos perder: todos os sábados às $14 \mathrm{~h}$. Íamos acompanhados com um grupo de crianças. Com o tempo tivemos que mudar o horário e a cada sábado combinar com as crianças o horário diferente e nos adaptar ao tempo delas.

Nas andanças pelas ruas do bairro nos damos conta da realidade dentro da qual se encontrava a escola. As crianças que iam conosco nos informavam sobre o funcionamento dos vários pontos do bairro dizendo quais os perigos, o que havia de bom, onde comprar os melhores doces, a igreja que freqüentavam, os muros que pulavam, as árvores que subiam, as pessoas que conheciam, enfim, a realidade dentro da qual se processa seu cotidiano. Intercalávamos nossas visitas com atividades de dobraduras, colagens, desenhos, por meio dos quais representavam lugares destacados na visita.

Nos demos conta de que este bairro, como tantos outros bairros de nosso país, se situa próximo a grandes empresas propiciando trabalho a homens e mulheres que saem para trabalhar nas diversas horas do dia revezando seus turnos. No contato com adultos que encontrávamos na rua perguntávamos sobre as necessidades do bairro, e apon- tavam o desemprego e a violência como fatores de preocupação.

As casas dos moradores muito simples eram "coladas" uma a outra e as grades enormes cobriam a entrada. Protegem-se de um modo individual, na solidão, nem um sinal de coletividade, organização, mobilização, tão importantes para a transformação (Prilleltensky \& Nelson, 2002).

No local próximo a escola, 3 quadras atrás do muro, num lugar discreto, pessoas moram em casas mais pobres feitas de papelão, de latas, de tábuas velhas, pedaços de tijolo. As ruas limpas e o tráfego de carros era pouco no entanto, giravam bicicletas e algumas charretes. Os moradores sentavam-se na rua conversavam em grupos. Pensamos até que ali poderia haver a possibilidade de uma organização de base pois parecem partilhar sua condição social e não há grades para se proteger e se esconder. Alguns moradores trabalham como catadores de papel, chapas, traficantes, nas empresas.

Próximo da escola existe uma praça e ali nos encontramos muitas vezes para ver as crianças subir nas enormes árvores e brincar. Acontecia nesta praça também o trabalho alternativo de troca de produtos suprindo necessidades vitais para alguns e para outros alimentando o vício do prazer imediato, da fuga. Foi ali que jovens e adolescentes nos disseram que este é o ponto de trabalho alternativo deles, ou seja, vendem drogas.

Começamos a perceber que os valores, conhecidos e internalizados por nós, começavam a mostrar-se de um modo diferente e teríamos que saber deles, lê-los a partir de uma perspectiva que possibilitasse uma reflexão libertadora de sujeitos inseridos numa sociedade que obriga a "tolerar" a violência como forma de sobreviver.

O valor do trabalho neste contexto, obrigou-nos a olhar para as diferenças sociais que ali se visualizavam e que refletem o contexto social maior. Vivemos numa sociedade em que o cotidiano das pessoas é invadido pelas adversidades impostas pelo capitalismo, economia globalizada. O trabalho humano neste sistema é reduzido ao emprego e ter a identidade de "trabalhador" neste contexto é submeter-se a regras de pessoa empregada. No entanto milhares de pessoas estão excluídas do emprego e sem trabalho remunerado levando-os a desintegração social. Por outro lado a sociedade exige o consumo de bens. Não consumir e não ser feliz se tornaram sinônimos. Não importa muito a vida do sujeito, importa ter e consumir. Somos coisas que consomem coisas, mercadoria (Guzzo, 2005).

As famílias são percebidas, de acordo com alguns relatos, vivendo situações de exclusão, de medo e ao mesmo tempo que convivem com a prolongada ausência de suas casas por causa do "emprego" ou por causa do "trabalho" o que dificulta um vínculo e relações familiares mais estreitas e estáveis. 
De acordo com Bronfenbrenner (1996) a família, hoje entendida de forma bastante abrangente, é um dos níveis de interação onde se dão as relações face a face ampliandoas para outros contextos. A família assim como a escola passam a constituir-se em espaços a partir dos quais o indivíduo se desenvolve de forma saudável e comprometido socialmente.

O contexto familiar, no entanto, é afetado por um sistema social mais amplo, por pessoas e grupos que a compõem, ou seja, está inserida em contextos culturais e sociais tornando-se o espaço no qual se articula a relação entre indivíduo e sociedade visando o bem estar (Mondim, 2005).

Esta realidade compõe as experiências dos adolescentes e crianças que vem para a escola nos sábados a tarde e embora não sendo muitos, fazem acontecer uma super movimentação: entram, saem, retornam, gritam, sobem os muros, telhados, nada tranqüilos, agitados e uma vez ou outra, ocupando-se de alguma atividade proposta pelos adultos. A atenção ao contexto do outro fará com que não nos surpreendamos diante das formas de manifestação destes e que, como percebemos, se dão nos mais variados modos possíveis, na sua diferença e criatividade. Possibilitará também a reflexão da própria ação do sujeito e a libertação levando-o a emancipar-se (Freire, 2005).

É relevante, por exemplo, ver e perceber que os sujeitos pertencentes a um único e mesmo bairro mostraram, de ponta a ponta, que coexistem culturas diferentes, formas diferentes de pensar a sociedade, valores diferentes. E cada um traz consigo a vivência dos afetos muitas vezes tolhidos, machucados, quebrados, projetos pessoais anulados pelo sistema que paralisa e adoece os indivíduos. Negar-se a olhar para a realidade, para o cotidiano, se torna, segundo Guzzo (2005), um ato de violência e levará a escola a agir de forma essencialmente punitiva, controladora, dominadora.

Neste chão e nesta situação o sentar ao lado deles, na grama, na cadeira, no banco da praça, e sem pressa ouvir suas histórias, admirar-se das coisas que contam e recontam, rir com eles, contar e andar, se tornaram modos imprescindíveis para quem deseja um desenvolvimento do indivíduo saudável, pois permitem conhecer o vizinho da casa, o amigo da escola, o companheiro de rua, a comunidade, a igreja, o bar que freqüentam, a música que curtem. Isto se torna um empreendimento e um modo de lutar pela própria emancipação, em outras palavras, humaniza os indivíduos e derruba a estrutura dominante de opressão, muitas vezes incorporado pela escola (Freire, 2005).

De acordo com Bronfenbrenner (1996), o conhecimento da realidade do outro nos leva ao afeto, ao vínculo e consequentemente ao desenvolvimento humano. O desenvolvimento humano se dá numa dinâmica em que o indivíduo passa a interação com outros ambientes proporcionando mudanças que se estendem no tempo e no espaço.
A pessoa em desenvolvimento é uma entidade em crescimento, dinâmica, que progressivamente penetra no meio em que reside e o reestrutura. Acontece aí uma reciprocidade entre ambiente e pessoa. Este ambiente inclui, segundo a ecologia do desenvolvimento humano, estruturas de micro-meso-exo e macrossistema (Bronfenbrenner, 1996, p. 18).

O movimento de ir e vir dos adolescentes e crianças para o "espaço escolar", dá-se como manifestação do desejo de estar com o outro. Este outro que possibilita a comunicação, participa e dá sentido às invenções e criações e com isto a conquista da autonomia. Ir para a escola tem o sentido da descoberta da importância do papel do outro em sua constituição pessoal e forma de viver. $O$ chão daquele espaço escolar torna-se o sustento da cultura, do pensamento, das possibilidades de tornar-se sujeito da própria história. No entanto, como lembra Freire (2005), para que haja a conquista da autonomia a escola deverá sair da neutralidade política e ideológica que anula a liberdade criativa de tantas crianças e jovens.

Movemo-nos em campo institucional e de acordo com Nasciutti (2003) "elas são manifestações e concretizações das realidades da vida em sociedade" (p.110). Ao ingressar em uma instituição os sujeitos se movem dentro de regras, códigos, ideologias, costumes, ao mesmo tempo que, na teimosia, atuam e participam na tentativa de manifestar sua singularidade.

É um pequeno mundo, uma pequena sociedade na qual vivemos. Por outro lado, é ali também que queremos ser reconhecidos em nossa singularidade, que queremos fazer valer nossos direitos e vontades, realizar nosso objetivos individuais. E todos ali buscam o mesmo (Nasciutti, 2003, p. 102).

A escola na sua função de instituição educativa e cultural convive com um sistema político e econômico e social adverso e vê-se "forçada" a acolher os filhos marcados pela desigualdade social. Neste contexto adverso a vida humana é mercantilizada e já não importa o que pensam as pessoas, o que elas sentem. "Crianças são excluídas ou rejeitadas em sua pobreza, sua forma de se vestir, seu espaço de morar ou viver, seu jeito de agir, falar ou mesmo sentir" (Guzzo, 2005, p. ).

De acordo com Prilleltensky, e Nelson (2002) a exclusão traz em sua origem um padrão idealizado de pessoas e com isto impõe uma cultura e conseqüentemente instaura-se um poder que anula todas as experiências humanas diferentes enquadrando-as num modo de compreensão ditado pela ideologia vigente, obstruindo necessidades coletivas, individuais e de relação.

Conforme Nasciutti (2003) a exclusão assim se dá num lugar específico institucionalizado repetindo o sistema mais amplo de exclusão. É preciso portanto olhar para a instituição e seus mecanismos, perceber práticas instituí- 
das e cristalizadas e possibilitar na prática cotidiana a emergência dos atores sociais.

De acordo com Freire (2005) para que surjam atores sociais, pessoas que empreendam um processo libertador dos seus grupos, da sua comunidade necessita-se criar espaços de autonomia dos sujeitos favorecendo a práxis na qual se une a ação e a reflexão sobre o mundo. A reflexão possibilita que haja uma crescente conscientização através da qual os sujeitos passam a ver e perceber a realidade que lhes se apresenta, em toda sua dinâmica, constituindo a partir disso sujeitos que fazem e refazem o mundo, atores sociais.

A experiência feita com os adolescentes que freqüentavam a escola nos sábados a tarde parece que mostra um pouco a ação dos sujeitos sobre sua realidade. Estes haviam feito, segundo relato destes, a experiência de passar um tempo na FEBEM e os motivos pelos quais foram levados a freqüentar aquela instituição eram quase sempre os mesmos: pequenos furtos, uso de drogas, fuga de casa. As famílias não conseguem lidar com tais situações e recorrem ao conselho tutelar que intervinha para a internação em instituições.

Muitos dos adolescentes, ao retornar buscavam a instituição escola como nova chance de se reintegrar na comunidade, no grupo social. Passamos a escutá-los todos os sábados sentando-nos no chão ouvindo músicas e nos inserindo nas atividades que eles propunham. Com o tempo nos tornamos parceiros e estes começaram a sugerir outros assuntos e propunham a sala de aula para ir conversar e não sermos interrompidos no nosso "bate papo" pois estava sempre mais interessante. Falavam das dificuldades que encontravam para re inserir-se nos grupos, do preconceito, do desemprego.

Iniciava-se ali um processo de reflexão sobre a realidade e de acordo com Freire (2005) ao tomar posse da mesma, desvelando-a em suas engrenagens se torna possível a atuação transformadora. A atuação dos adolescentes se deu com a prática do grafite inicialmente em folhas de papel e depois olharam para o muro da escola. Está postura de "por-se em atividade", agir sobre a realidade, sugere que eles mostrem sua visão de mundo, indo além do mutismo imposto pela força esmagadora que paralisa os indivíduos.

O projeto de grafitar o muro se fez num processo lento e de reflexão. Foram vários sábados sentados em frente ao muro, imaginando cores, sugerindo temas e figuras que mostrasse a realidade. "Esta procura temática converte-se numa luta por uma consciência da realidade e uma consciência de si, que fazem desta procura o ponto de partida do processo de educação e da ação cultural de tipo libertador" (Freire, 2005, p. 37).

Isto propõe pensar o espaço escolar como lugar no qual as pessoas que ali transitam, encontram facilitadores de aprendizagem. Estes facilitadores se põem diante do aluno com atitudes que de fato fazem acontecer o pleno desenvolvimento e que correspondem ao exposto acima: ouvir e criar relações de afeto (Rogers, 1977).

Quando o facilitador é uma pessoa verdadeira, sendo o que é, e se relaciona com o aprendiz sem se vestir de uma fachada, é muito mais provável que seja eficaz. Isto significa que os sentimentos que experimenta estão a seu alcance, disponíveis à sua percepção, e que ele é capaz tanto de viver e ser estes sentimentos como de comunicá-los se o desejar. Significa que ele vem para um encontro direto, pessoal, com o aprendiz, chegando-se a ele numa base de pessoa-a-pessoa. Significa que ele está sendo ele mesmo, não se negando (Rogers, 1977, p. 149).

Neste contexto e dinâmica envolvendo o educando e educador, as experiências pessoais ganham sentido particular uma vez que são atividades preciosas reconstruídas pelo próprio aluno. O educando, como pessoa, é considerado situado no mundo. Como pessoa ele é único e num processo contínuo de descoberta de seu próprio ser, ligando-se a outras pessoas e grupos. Isto the possibilita a novidade, a descoberta de coisas novas, num projeto permanente e inacabado (Rogers, 1977).

De acordo com este mesmo autor o ser humano significa: ser uma totalidade, um organismo em processo de integração, ser independente, diferente. Neste, os sentimentos e as experiências são importantes como fator de crescimento. Ser pessoa humana significa interagir com outras pessoas, compreendida e aceita como tal. A pessoa humana é alguém capaz de fazer-se crescer. Isto propõe pensá-la numa dinâmica de desenvolvimento contínuo, numa dinâmica progressiva.

Este desenvolvimento se dá na reciprocidade entre ambientes. Nestes a pessoa interage, se move, vivencia sua experiência pessoal e percebe a dinâmica motivadora que favorece seu desenvolvimento Bronfenbrenner (1996).

Partindo de sua percepção do mundo que a cerca, a pessoa recebe estímulos, atribui significado às experiências e re constrói em si o mundo exterior e será a escola o espaço no qual o adolescente e a criança encontrarão as condições para que cresça a consciência de significar suas experiências, reconstrua, pela sua ação, o ambiente (Rogers, 1977).

O ambiente se torna uma das condições necessárias para que o desenvolvimento saudável aconteça incluindo as várias estruturas dentro do qual o indivíduo atua, interage, se faz (Bronfenbrenner, 1996).

É a partir destes ambientes, denominados de comunidades, que o indivíduo se vincula, ampliando seu espaço para outras comunidades, incluindo-se em grupos. Os grupos no entanto se tornam comunidades quando a individualidade da pessoa constrói o grupo ao qual pertence Segundo (Heller, 2000).

De acordo com Freire (2005) não todo grupo pode ser considerado comunidade mas pode chegar a ser comuni- 
dade. Isto acontece quando a atividade do indivíduo explicitar a essência humana, isto é, quando for uma ação libertadora, pensada e refletida.

Quando os indivíduos adentram-se num espaço, no nosso caso, a escola, deveriam estar carregados de motivos para escolher aquele ambiente. Devem estar atentos em escolher uma comunidade de conteúdo positivo, para que sua individualidade se desenvolva. Escolher um ambiente para interagir faz parte da essência do ser humano. $\mathrm{O}$ ambiente escolhido tornar-se-á um lugar da manifestação da individualidade, colocando toda sua riqueza enquanto ser humano o que irá favorecer o valor da comunidade e o valor pessoal, pois ambos se enriquecem com o conteúdo positivo de cada um (Heller, 2000).

A mesma autora sugere que os ambientes nos quais se insere ou é inserido, oferecem outras numerosas objetivações para desenvolver sua individualidade: a arte, ciências, esporte, dança, valores.

Para Rogers (1977) uma vez que olhamos para o indivíduo como sujeito da educação, do espaço, a comunidade, ele será capaz de arrancar possibilidades e de recriar-se, o importante seria criar condições nas quais pudessem tornarse pessoas de iniciativas, de responsabilidade, de autodeterminação, de discernimento, que soubessem aplicar-se a aprender as coisas que lhes servirão para a solução de seus problemas e que tais conhecimentos os capacitassem a se adaptar com flexibilidade às novas situações, aos novos problemas, servindo-se da própria experiência, com espírito livre e criativo. Seria, enfim, a criação de condições nas quais o aluno pudesse tornar-se pessoa que soubesse colaborar com os outros, atuar sem medo.

Isto corresponde ao que diz Freire (2005) ao falar de sujeitos conscientizados, ou seja, "aqueles que estão conscientizados apoderam-se de sua própria situação, inseremse nela para transformá-la e a conscientização não pode pretender nenhuma neutralidade" (p. 90 ). Isto exige do educador uma postura "simplesmente" humana, ou seja, deverá estar lado a lado com as pessoas construindo com elas a mútua humanização através de um pensamento crítico e recriando com confiança as situações dentro das quais se movem.

De acordo com Guzzo (2005) as relações humanas nos vários contextos são atravessadas pelo consumo tornandose mais importantes do que a vida em comunidades. Neste contexto de consumo o tempo, para o que Freire chama de mútua humanização, se tornou difícil (2005).

Diante desta realidade consumista na qual o sujeito vale por aquilo que tem e por aquilo que consome, a atuação do psicólogo crítico e participante poderá favorecer a organização das comunidades criando infraestruturas para a defesa de seus direitos através de processos participativos, desenvolvendo a reflexão dos valores que promovam o bem estar pessoal, relacional, coletivo, de crescimento pessoal e a mudança social (Prilleltensky \& Nelson 2002).
Para Silva (2002) a participação em trabalhos de organização de comunidades possibilita a promoção de saúde e cidadania que por sua vez favorece que os sujeitos estabeleçam metas e objetivos mantendo uma percepção realista do mundo; integrem o bem estar afetivo e consigam manter um estado de bem estar tanto em nível geral como específico; atuem de forma autônoma e competente dentro do contexto sócio cultural ao qual pertencem; tenham uma percepção de si física e mentalmente saudável, capaz, atraente, respeitável e desenvolva uma percepção positiva de si; desenvolva vínculos afetivos; realize trabalhos produtivos e criativos mesmo se inserido num meio desafiador e numa sociedade causadora de "mal estares" sociais.

Este é o compromisso ético e político do psicólogo e educador o qual deverá proporcionar, pela sua ação e participação, o bem estar dos que ali se encontram, contribuir para a formação de uma identidade coletiva e emancipação da pessoa (Guzzo, 2005).

\section{Referências}

Alves, P. C. (1997). Emancipação frente à colonização e as políticas de identidade na adolescência. Tese de Doutorado não-publicada, Pontifícia Universidade Católica de São Paulo. São Paulo, SP.

Bronfenbrenner, U. (1996). A ecologia do desenvolvimento humano. Experimentos naturais e planejados. Porto Alegre. ArtMed.

Ciampa, A. C. (2001). A estória do Severino e a história da Severina. Um ensaio de psicologia social. São Paulo, Brasiliense.

Guzzo, R. S. L. (2005). Escola amordaçada: compromisso do psicólogo com este contexto. In A. M. Martinez (Ed.), Psicologia escolar e compromisso social (pp. 17-29). Campinas.

Freire, P. (1993). Conscientização teoria e prática da libertação. São Paulo. Centauro.

Lane, S. (2003). Psicologia social e comunitária: da solidariedade à autonomia. Petrópolis, RJ: Vozes.

Heller A. (2000). O cotidiano e a história. Rio de Janeiro: Paze Terra. Mondim, E. M. C. (2005). Um olhar ecológico da família sobre o desenvolvimento humano. Psicologia Argumento, 23(41), 25-35.

Prilleltensky, I. \& Nelson, G. (2002). Doing Psychology Criticaly. Hardback, 7-29.

Rey,F.G.(1993). Personalidad, saludy modo de vida. México: UNAM Iztacala.

Silva, R. C. (2002). Psicologia Social da Saúde e a construção de um conceito positivo de saúde. In R. C. Silva (Ed.), Metodologias participativas para trabalhos de promoção de saúde e cidadania (pp. 26-27). São Paulo: Vetor.

Salete Petes é religiosa franciscana, formada em filosofia pela USF-SP e em psicologia pela Uniararas-SP. Atualmente atua no atendimento individual e organização e articulação de grupos incluindo a escola, família e sociedade.

salete peters@yahoo.com.br

Gustavo Gonçalves da Cunha. Psicólogo formado em 2005 pela Uniararas. Atuação voltada a Recursos 
Humanos com Seleção e Recrutamento. Realizando aperfeiçoamentos voltados a Saúde e a Comunidade.

Raquel Tizzei é Psicóloga pela PUC-Campinas. Professora de psicologia na Uniararas-SP. Avenida Dr. Maximiliano Baruto, 500 - CEP: 13607-339, Araras/SP tizzuca.@hotmail.com
Uma experiência em Psicologia, Educação e Comunidade

Salete Peters, Gustavo Gonçalves e Raquel Tizzei

Recebido: 03/04/2006

$1^{a}$ revisão: 21/09/2006

Aceite final: 15/09/2006 